\title{
PENGARUH MODEL PEMBELAJARAN TEAMS GAMES TOURNAMENT (TGT) TERHADAP PEMAHAMAN KONSEP MATEMATIS SISWA SEKOLAH DASAR
}

\author{
Fatkhul Arifin $^{1 *}$, Ziaratul Fadillah ${ }^{2}$, Rohmat Widiyanto ${ }^{3}$ \\ Program Studi Pendidikan Guru Madrasah Ibtidaiyah, \\ Universitas Islam Negeri Syarif Hidayatullah, Jakarta, Indonesia \\ *Email: fatkhul_arf@uinjkt.ac.id
}

\author{
Website: \\ https://jurnal.uinantasari.ac.id/index.php/adzka
}

Received: 12 Agustus 2020; Accepted: 18 Desember 2020; Published: 29 Desember 2020

DOI: $10.18952 /$ aladzkapgmi.v10i2.3873

\begin{abstract}
This research is done with a purpose to determine the effect of applying the learning model of Teams Games Tournament (TGT) on understanding the mathematical concepts of elementary school students. The research was carried out in Madrasah Ibtidaiyah (MI) Pembangunan Islamic University of Syarif Hidayatullah Jakarta academic year 2019/2020. The research method used is quasi-experiment and the research design is Non-Equivalent Control Group Design. The sample was selected by using cluster random sampling which is the sample selected randomly so that it is obtained class II E as the experimental class and class II F as the control class. Concept understanding refers to indicators of understanding by Russefendi that is: translation, interpretation, and extrapolation. The test instrument is a description of 6 questions and the non-test instrument is in the form of interview and observation sheets. Based on the result of hypothesis testing using the t-test at a significance level $5 \%$ obtained a value of 0,003 with a value of $<0,05$ and the result of the calculation of the amount of influence with a value of 0,42 in the low category. So, it is concluded that there is an influence on the learning model of TGT on understanding the mathematical concepts of elementary school students.
\end{abstract}

Keywords: quasi experiment; teams games tournament; understanding of mathematical concepts

\begin{abstract}
ABSTRAK
Penelitian ini dilakukan dengan tujuan untuk mengetahui pengaruh penerapan model pembelajaran Teams Games Tournament (TGT) terhadap pemahaman konsep matematis siswa Sekolah Dasar. Penelitian dilaksanakan di Madrasah Ibtidaiyah (MI) Pembangunan Universitas Islam Negeri (UIN) Syarif Hidayatullah Jakarta tahun ajaran 2019/2020. Metode penelitian yang digunakan adalah metode kuasi eksperimen dan desain penelitiannya adalah NonEquivalent Control Group Design. Sampel dipilih secara teknik cluster random sampling dimana sampel dipilih secara acak sehingga diperoleh kelas II E sebagai kelas eksperimen dan kelas II F sebagai kelas kontrol. Pemahaman konsep mengacu kepada indikator pemahaman oleh Russefendi yaitu: translasi, interpretasi, dan ekstrapolasi. Instrumen tes berupa uraian berjumlah 6 soal dan instrumen nontes berupa lembar wawancara dan observasi. Berdasarkan hasil pengujian hipotesis dengan menggunakan uji-t pada taraf signifikansi 5\% diperoleh nilai 0,003 yang bernilai $<0,05$ dan hasil perhitungan besaran pengaruh dengan nilai 0,42 kategori rendah. Jadi disimpulkan bahwa terdapat pengaruh model pembelajaran TGT terhadap pemahaman konsep matematis siswa Sekolah Dasar.
\end{abstract}

Kata Kunci: kuasi Eksperimen; model pembelajaran tipe teams games tournament; pemahaman konsep matematis. 


\section{PENDAHULUAN}

Pendidikan merupakan proses untuk mengembangkan potensi diri dalam mencapai manusia yang seutuhnya. Sependapat dengan Susanto yang menyatakan dengan menempuh pendidikan merupakan cara yang terorganisir dan berlangsung sepanjang hayat yang akan membina seseorang menjadi manusia yang berbudaya, dewasa bahkan menjadi manusia yang paripurna (Susanto, 2013). Definisi pendidikan juga dijelaskan dalam Undang-Undang Sistem Pendidikan Nasional (UUSPN) No 20 tahun 2003 yang berisi:

Pendidikan adalah usaha sadar dan terencana untuk mewujudkan suasana belajar dan proses pembelajaran agar peserta didik secara aktif mengembangkan potensi dirinya untuk memiliki kekuatan spiritual keagamaan, pengenalan diri, kepribadian, kecerdasan, akhlak mulia, serta keterampilan yang diperlukan dirinya, masyarakat, bangsa dan negara (UUSPN 20 Tahun 2003).

Usaha sadar dan terencana ini tentunya berorientasi untuk mengembangkan semua aspek potensi diri pada setiap siswa, seperti aspek kognitif, afektif dan psikomotorik. Hal ini dapat ditempuh melalui proses pembelajaran yang direncanakan sedemikian rupa untuk mencapai tujuan yang dikehendaki. Pembelajaran terdiri atas berbagai komponen dalam suatu sistem yang saling keterkaitan dengan lainnya. Komponennya meliputi tujuan, materi, metode, dan evaluasi (Rusman, 2014). Oleh sebab itu, seorang guru harus memperhatikan komponen tersebut agar tercipta ilklim belajar yang menunjang.

Salah satu pembelajaran penting yang diajarkan sejak sekolah dasar adalah pembelajaran matematika. Pembelajaran matematika itu identik dengan ide yang abstrak berupa simbol-simbol sehingga setiap konsep matematika harus dimanipulasi agar mudah untuk dipahami (Susanto, 2013). Jadi tidak hanya sekedar mengetahui konsep namun dalam belajar matematika perlu adanya cara untuk memahami sehingga mampu mengkontruksi pengetahuannya.

Pemahaman sangat berbeda dengan menghafal atau sekedar mengetahui, yakni dengan menghafal berarti proses pembelajaran hanya memberikan pengetahuan berupa teori-teori tanpa adanya proses pemahaman yang mendalam sehingga pengetahuannya mudah dilupakan. Sependapat dengan Heruman yang menyatakan setiap konsep abstrak yang baru dipahami oleh siswa dalam pembelajaran matematika perlu diberikan penguatan, agar ingatan mereka bisa bertahan lama dan mengendap dalam pola pikir serta pola tindakannya (Heruman, 2010). Hal ini akan tercipta suatu pembelajaran bermakna untuk siswa sehingga dapat diterapkan dalam perilaku kehidupan sehari-hari.

Konsep-konsep matematika ini terstruktur secara sistematis dari langkah ke langkah dan hierarkis dari yang paling sederhana sampai yang kompleks. Pemahaman dan penguatan suatu konsep merupakan prasyarat yang mendasar untuk mempelajari konsep materi selanjutnya. Oleh sebab itu kemampuan pemahaman konsep merupakan hal yang sangat penting untuk belajar materi matematika agar proses pembelajaran berlangsung menjadi lebih bermakna (Heruman, 2010). Dengan kata lain bahwa demi tujuan pembelajaran matematika maka perlu menanamkan keterampilan dalam memahami suatu konsep.

Disimpulkan bahwa dalam belajar matematika penting memiliki kemampuan memahami suatu konsep. Hal ini disebutkan dalam standar kompetensi matematika yang dirumuskan dalam kurikulum salah satunya mencakup pemahaman konsep (Heruman, 2010). Dalam hal ini pemahaman didefinisikan sebagai kemampuan seseorang dalam mengartikan konsep, menafsirkan pengetahuan kemudian menerjemahkan pemahaman dari berbagai informasi sehingga mampu menyatakan pengetahuan yang telah diterimanya dengan caranya sendiri (Uno, 2011). 
Lebih lanjut menurut NCTM (The National Council for Teacher of Mathematics) dalam Fitriyane mengungkapkan bahwa alasan penting mengajarkan pemahaman tentang sebuah konsep sangat bermanfaat pada abad 21 ini, karena siswa perlu memiliki pemahaman konseptual agar siswa berkembang dan mampu memecahkan masalah sebagai orang yang dewasa di lingkungan yang semakin mengalami perubahan (Fitriyane, 2018). Pernyataan ini sangat memperkuat bahwa pemahaman konseptual sangat berkaitan dengan pembelajaran matematika dan lebih dari itu untuk mengikuti perkembangan zaman saat ini. Dampaknya siswa terbiasa mampu memahami sesuatu hal dengan benar.

Namun dari hasil wawancara dengan salah satu guru MI Pembangunan UIN Jakarta yaitu Ibu Himatun,M.Pd pada Rabu, 17 Juli 2019. Diperoleh informasi bahwa dalam pembelajaran matematika cenderung menggunakan hafalan sehingga masih rendah kemampuan siswa untuk memahami suatu konsep. Pembelajaran matematika dilakukan dengan pola instruksi, bukan konstruksi dan rekonstruksi pengetahuan. Bahkan tanpa memberi kesempatan pada siswa untuk menentukan sendiri arah mana siswa ingin berekplorasi dalam menemukan pengetahuan yang bermakna bagi dirinya (Rahmita, 2016: 181-190). Akibatnya pembelajaran matematika di sekolah hanya bersifat hafalan dan bukan melatih pola pikir Sistem pembelajaran matematika yang dihafal juga ditegaskan oleh Ausubel dalam teorinya yang berkaitan dengan cara manusia memperoleh pengetahuan, mengkontraskan belajar bermakna dengan belajar hafalan (Rahmita, 2016: 181-190). Karakteristik siswa kelas II yang masih suka bermain semakin membuat suasana pembelajaran di dalam kelas kurang kondusif sehingga siswa tidak memahami konsep dan tidak mampu menjawab pertanyaan.

Berdasarkan hasil observasi awal, beberapa siswa juga masih memiliki rasa malu-malu sehingga tidak terjalin komunikasi yang baik diantara siswa. Di dalam kelas terdapat siswa yang aktif dan menguasai kelas, ada juga yang hanya menjadi pendiam. Selain itu, masih ada juga siswa yang suka menggambar ataupun mengobrol sendiri ketika proses pembelajaran. Peneliti melakukan tes awal untuk mengetahui pemahaman awal siswa pada konsep pembagian. Diperoleh nilai rata-rata yang didapatkan pada tes awal dari dua kelas adalah 38,29 dan 43,96. Dari hasil yang telah diperoleh dapat disimpulkan bahwa nilai pemahaman konsep siswa masih terkategori rendah pada materi pembagian. Penelitian dilaksanakan pada kelas II Madrasah Ibtidaiyah dengan karakteristik siswanya yaitu senang bermain dan bekerja dalam kelompok (Hosnan, 2016). Jika dikaitkan dalam proses pembelajaran maka model pembelajaran yang diterapkan dapat disesuaikan dengan karakteristik siswa.

Memperhatikan masalah yang ada di atas maka pembelajaran matematika perlu menerapkan sebuah model pembelajaran yang dapat disesuaikan dengan karakteristik siswa SD/MI sehingga berimplikasi memudahkan siswa dalam memahami suatu konsep. Peneliti kemudian menentukan model pembelajaran agar mengatasi hal tersebut dengan cara nenggunakan model pembelajaran Teams Games Tournament (TGT). Model Teams Games Tournament dapat menciptakan lingkungan kelas yang efektif menjadikan siswa lebih berperan aktif dalam proses pembelajaran dan secara konsisten menerima dorongan untuk kinerja yang sukses serta mampu memperjelas pemahaman konsep yang sedang dipelajari (Annurwanda, 2018). Diharapkan melalui model TGT ini siswa mendapatkan pengalaman belajar yang baru dan tidak merasa bosan di kelas (Ardian, 2015).

Penerapan model TGT mampu membentuk kelompok siswa yang bekerja sama dalam tim sehingga harapannya setiap anggota bertanggung jawab memastikan anggota timnya mencapai tujuan, yakni menguasai pelajaran tersebut dan dapat memahami dengan baik (Slavin, 2005). Hal ini akan membuat siswa mampu mengutarakan pengetahuan yang diterimanya kebentuk lain. Lalu kelompok yang telah berhasil memahami konsep akan melaksanakan games tournament, disini siswa yang paham akan mampu menafsirkan pengetahuannya baik dalam bentuk gambar, grafik, dll. Kelompok yang mendapatkan skor tertinggi akan dikatakan 
pemenang, dan perwakilan dari kelompok tersebut harus ada yang mampu menyimpulkan maupun membedakan pengetahuan yang ada.

Hasil penelitian Devita memperkuat pernyataan bahwa dengan menggunakan model TGT dalam proses pembelajaran memiliki nilai lebih tinggi daripada menggunakan model pembelajaran konvensional baik secara keseluruhan maupun siswa yang berkemampuan awal tinggi, sedang, dan rendah (Devita, 2017). Berdasarkan hal-hal yang dikemukakan, peneliti tertarik untuk melakukan penelitian menggunakan model pembelajaran Teams Games Tournament (TGT) terhadap pemahaman konsep matematis siswa pada Sekolah Dasar.

\section{METODE}

Penelitian ini merupakan penelitian kuantitatif dengan bentuk metode eksperimen yang digunakan adalah kuasi eksperimen. Penelitian ini untuk mengetahui pengaruh model pembelajaran kooperatif tipe teams games tournament terhadap pemahaman konsep matematis siswa pada Sekolah Dasar. Desain penelitian yang digunakan adalah Non-Equivalent Control Group Design. Populasi dalam penelitian ini adalah seluruh kelas II MI Pembangunan UIN Jakarta sedangkan sampel dalam penelitian ini adalah dua kelas yang dipilih dari keseluruhan populasi dengan teknik Cluster Random Sampling dipilih secara acak sehingga dalam penelitian ini diperoleh dua kelas, yaitu kelas II E berjumlah 28 siswa sebagai kelas eksperimen dan kelas II F berjumlah 28 siswa sebagai kelas kontrol. Instrumen yang digunakan dalam penelitian ini berupa wawancara, lembar observasi dan tes pemahaman konsep. Data kuantitatif yang berhasil dikumpulkan dan dianalisis menggunakan SPSS 22,0 kemudian ditarik kesimpulan dari hipotesis penelitian dengan teknik analisis data yang digunakan adalah uji normalitas, homogenitas dan hipotesis.

\section{HASIL PENELITIAN DAN PEMBAHASAN}

\section{A. Hasil Penelitian}

Hasil analisis data pretest dan posttest terhadap kelompok eksperimen dan kontrol menggunakan perhitungan aplikasi SPSS 22,0. Hasil pretest menunjukan bahwa data sampel yaitu 56 siswa dengan jumlah skor kelas eksperimen sebanyak 1072 dan kelas kontrol 1231. Nilai rata-rata nilai pretest kelas eksperimen 38,29 dan 43,96 nilai rata-rata kelas kontrol. Hal ini menunjukan bahwa nilai rata-rata kelas eksperimen lebih rendah daripada kelas kontrol. Berdasarkan hasil pretest juga menunjukan bahwa nilai rata-rata kedua kelas tidak berbeda jauh sehingga dapat disimpulkan kedua kelas memiliki pemahaman yang sama. Adapun nilai maksimum untuk kelompok kontrol dan eksperimen sama yaitu mendapatkan nilai 54. Begitu pula nilai minimum kelas kontrol dan eksperimen sama yaitu mendapatkan nilai 29. Selain itu, standar deviasi dari kelompok eksperimen 8,114 lebih tinggi dibandingkan kelas kontrol yaitu 8,039. Hal ini berarti keberagaman nilai kelompok eksperimen lebih tinggi dibandingkan nilai kelompok kontrol. Ditinjau dari nilai modus, kelas kontrol mendapat nilai 50 lebih tinggi dibandingkan kelas eksperimen yaitu 29. Kelas kontrol mendapat nilai median sebesar 46,00 juga lebih tinggi dibandingkan kelas eksperimen yaitu 38,00.

Hasil posttest menunjukan bahwa nilai rata-rata kelompok eksperimen sebesar 85,39 lebih tinggi dibandingkan kelompok kontrol memiliki rata-rata 80,00. Selain itu, nilai maksimum dan nilai minimum pada kedua kelompok mengalami peningkatan dibandingkan pretest, nilai maksimum untuk kelompok eksperimen sebesar 96 lebih tinggi daripada kelompok kontrol yaitu 92, dan nilai minimum kelompok eksperimen sebesar 75 juga lebih tinggi dibandingkan nilai minimum kelompok kontrol yaitu 67. Kemudian standar deviasi kelompok kontrol lebih tinggi yaitu 6,600 sedangkan kelompok eksperimen 6,124. Hal ini berarti keberagaman nilai kelompok kontrol lenih tinggi dibandingkan kelompok eksperimen. Ditinjau dari nilai modus, kelompok eksperimen dan kontrol memiliki nilai yang sama yaitu 83. Ditinjau dari nilai median menunjukan bahwa hasil dari kelompok eksperimen sebesar 85 
lebih tiggi dibandingkan kelompok kontrol yaitu 79. Nilai pemahaman konsep matematis siswa lebih tinggi setelah diterapkannya model pembelajaran Teams Games Tournament, hal tersebut dapat dilihat dari hasil pretest dan posttest yang dilakkan pada kelas kksperimen dan kelas kontrol.

Sebelum dilakukan pengujian hipotesis terlebih dahulu dilakukan pengujian prasyarat analisis data berupa uji normalitas dan uji homogenitas yang diuji menggunakan SPSS 22,0. Uji normalitas pretest menggunakan saphiro wilk pada kelas kontrol dan eksperimen diperoleh hasil $>0,05$ yaitu 0,010. Uji normalitas posttest pada kelas kontrol diperoleh hasil 0,325 dan kelas eksperimen diperoleh hasil 0,138. Hal ini menunjukan bahwa data tersebut berdistribusi normal. Uji homogenitas juga menggunakan aplikasi SPSS 22,0 One-Way Anoval diperoleh hasil pretest kelas eksperimen dan kontrol siginifikannya 0,914 dan posttest kelas eksperimen dan kontrol diperoleh hasil 0,735 . Hal ini menunjukan bahwa varian yang dimiliki oleh kedua kelas adalah homogen karena $>0,05$.

Hasil analisis uji-t menunjukan bahwa terdapat pengaruh menggunakan model pembelajaran kooperatif tipe Teams Games Tournament terhadap pemahaman konsep matematis siswa Sekolah Dasar. Hal tersebut ditunjukan dari hasil perhitungan yang memperoleh nilai 0,003 <0,005. Penggunaan model pembelajaran TGT kemudian dilakukan perhitungan besaran pengaruh yang diperoleh hasil 0,42 dengan kategori rendah. Observer juga menilai guru menggunakan lembar observasi bahwa guru sudah melakukan seluruh tahapan model pembelajaran kooperatif tipe Teams Games Tournament dan sesuai rencana pembelajaran.

\section{B. Pembahasan}

Pemahaman konsep matematis merupakan salah satu aspek yang sangat penting dalam pembelajaran, dengan memahami suatu konsep maka yang diharapkan kemampuan siswa dapat berkembang dalam setiap pembelajaran yang akan dipelajari. Memahami merupakan tindak lanjut dari kegiatan mengingat. Dengan pemahaman, siswa mampu membuktikan pemahamannya yang diperoleh dari hubungan yang sederhana diantara fakta-fakta atau konsep (Arikunto, 2013). Dalam hal ini siswa yang sudah benar-benar memahami maka mampu mengolah fatkta-fakta yang akan diutarakan olehnya.

Pemahaman menurut Bloom diartikan sebagai kemampuan untuk menyerap arti dari materi atau bahan yang dipelajari. Hal ini sesuai dengan konsep matematika yang masih abstrak berisi simbol-simbol maka konsep matematika harus dipahami terlebih dahulu (Susanto, 2013). Oleh sebab itu untuk belajar matematika yang berupa simbol maka perlu adanya keterampilan dalam memahami konsep. Pemahaman disini dapat diartikan dengan kemampuan seseorang dalam mengartikan, menafsirkan, menerjemahkan atau menyatakan sesuatu dengan caranya sendiri tentang pengetahuan yang pernah diterimanya (Uno, 2011).

Penelitian ini dilaksanakan pada kelas II Madrasah Ibtidaiyah dengan kisaran usia 8 tahun yang memiliki karakteristik dan kebutuhan diantaranya senang bermain dan bekerja dalam kelompok (Hosnan, 2016). Jadi seorang guru hendaknya dalam merancang suatu model pembelajaran dapat menyesuaikan dengan karakteristik dan kebutuhan siswa sehingga yang diharapkan akan memudahkan siswa dalam memahami suatu konsep.

Model pembelajaran kooperatif tipe teams games tournament dapat dijadikan sebagai alternatif untuk memahami konsep abstrak dalam pembelajaran matematika dengan materi konsep pembagian. Pelaksanaan model TGT ini dapat menciptakan lingkungan kelas yang efektif. Siswa terlibat aktif dalam proses pengajaran dan secara konsisten menerima dorongan untuk kinerja yang sukses serta mampu memperjelas pemahaman konsep yang sedang dipelajari (Annuarwanda, 2018).

Pelaksanan model pembelajaran kooperatif tipe Teams Games Tournament memerlukan beberapa tahapan sebagai jalan berlangsungnya pembelajaran. Pada penelitian ini 
menggunakan teori Isrok'atun dan Rosmala (Isrok'atun, 2018). Dengan langkah awal penyajian kelas dan membentuk tim secara heterogen membuat siswa mampu mengartikan berbagai pengetahuan yang diperolehnya. Langkah selanjutnya yang membedakan dengan model pembelajaran yang lain adalah adanya permainan turnamen. Dalam sebuah turnamen siswa diberikan suatu pertanyaan-pertanyaan yang akan membuat siswa mampu menafsirkan pengetahuan yang mereka miliki, sehingga akan menambah skor pada kelompok mereka. Siswa diminta untuk menyimpulkan pengetahuannya kemudian akan dihitung skor yang tertinggi akan mendapatkan penghargaan. Langkah-langkah model pembelajaran TGT dapat digambarkan sebagai berikut:

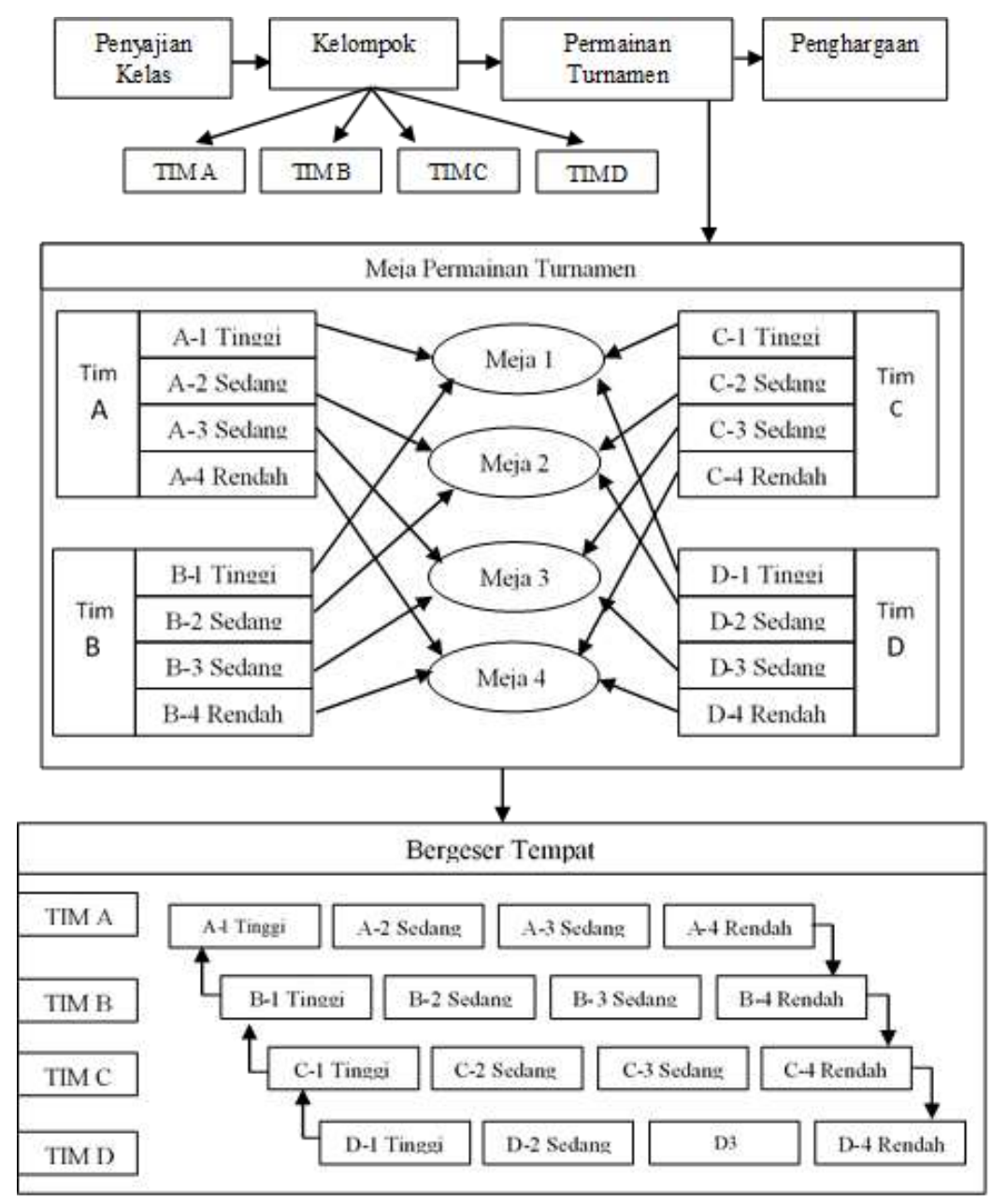

Gambar 1. Langkah pembelajaran TGT

Gambar 1 menjelaskan langkah-langkah pembelajaran TGT dimana terdapat 4 tim kelompok setiap tim terdiri dari 4 anggota. Kemudian tim kelompok dibentuk terdiri dari berbagai kemampuan seperti yang memiliki kemampuan tinggi, sedang dan rendah (heterogen). Harapannya agar anggota tim saling membantu dan berbagi informasi dengan anggotanya agar dalam satu tim secara kompak mampu memenangkannya.

Adanya sebuah kerjasama dalam TGT tentunya menjadi nilai pluas pada model ini, karena siswa yang faham bisa mengajarkan meraka yang belum faham. Selain itu adanya kompetisi untuk memenangkan permainan menjadikan motivasi bagi setiap kelompok untuk memahami materi yang diberikan oleh guru. Jika salah satu anggota kelompok tidak faham dengan materi yang diberikan maka kelompok tersebut akan mendapat hukuman (punishment) 
pengurangan poin. Motivasi sangat perpengaruh untuk menjaga mood siswa agar tetap semangat dalam belajar. Disinilah peran TGT dalam pembelajaran.

Jadi dapat disimpulkan dari penjelasan gambar 1, terdapat pengaruh model TGT terhadap pemahaman konsep matematis siswa sekolah dasar. Gambar 1 menjelaskan bahwa penempatan posisi duduk yang diacak sesuai dengan siswa yang mempunyai pemahaman tinggi terhadap konsep matematika dengan siswa yang kurang faham. Sehingga siswa yang faham bisa membimbing siswa yang kurang paham. Hal ini diperkuat dari penelitian sebelumnya yang dilakukan oleh Abdus Salam, dkk yang berjudul Effects of using Teams Games Tournaments (TGT) Cooperative Technique for Learning Mathematics in Secondary Schools of Bangladesh. Berdasarkan hasil penelitian yang telah dilakukan, dapat diketahui bahwa ada perbedaan signifikan antara pretest dan postest sebelum dan sesudah diberikan perlakuan, dilihat dari perhitungan stastistik dengan sig 2-tailed $=0,00 \mathrm{p}<0,05$. Hal ini menunjukan bahwa ada pengaruh model pembelajaran TGT terhadap pembelajaran matematika (Salam, 2015).

\section{PENUTUP}

Berdasarkan data diatas dapat disimpulkan bahwa penerapan model pembelajaran kooperatif tipe Teams Games Tournament berpengaruh terhadap pemahaman konsep matematis siswa Sekolah Dasar. Hal tersebut dibuktikan dengan hasil analisis data yang menunjukkan bahwa nilai rata-rata posttest kelas eksperimen lebih tinggi yaitu 85,39 dibandingkan nilai ratarata postest kelas kontrol yaitu 80,00 . Hasil postest tersebut diperkuat dengan hasil pengolahan data menggunakan pengujian hipotesis (Uji-t) menggunakan program SPSS yang memperoleh nilai $0,003<0,05$. Berdasarkan hasil pengujian dapat diketahui bahwa terdapat pengaruh yang signifikan penggunaan model pembelajaran kooperatif tipe Teams Games Tournament (TGT) terhadap pemahaman konsep matematis. Penggunaan model pembelajaran ini memberikan pengaruh dalam kategori rendah. Hal ini berdasarkan pada hasil perhitungan uji pengaruh (effect size) dengan rumus Cohen's yang diperoleh hasil 0,42.

Agar dalam penelitian selanjutnya dapat lebih baik, terdapat saran terkait hasil penelitian pada skripsi ini sebagai berikut: (1) Guru dapat menjadikan model pembelajaran kooperatif tipe teams games tournament sebagai alternatif dalam meningkatkan pemahaman konsep matematis materi pembagian. Pada pelaksanaanya dapat dikombinasikan dengan penggunaan media agar lebih mudah untuk memahami; (2) Dalam pelaksanaan model pembelajaran kooperatif tipe teams games tournament sebaiknya merencanakan pembelajaran dengan baik agar waktu yang digunakan lebih efektif dan tujuan pembelajaran dapat tercapai; (3) Sekolah dapat menerapkan model pembelajaran kooperatif tipe teams games tournament sebagai alternatif untuk meningkatkan kualitas pendidikan khususnya dalam pembelajaran matematika dengan materi pembagian; (4) Pembaca dapat menjadikan hasil penelitian ini sebagai suatu bahan kajian yang perlu diteliti lebih lanjut dan mendalam dengan sampel yang lebih besar atau untuk mengukur kemampuan matematis yang lain.

\section{DAFTAR PUSTAKA}

Annurwanda, Pradipta. (2018). The Effect of Teams Games Tournamen On Mathematics SelfEfficacy in Junior High Schools. SHS Web Conferences 42. 1-6.

Arikunto, Suharismi. (2013). Dasar - dasar Evaluasi Pendidikan. Jakarta: Bumi Aksara.

Devita, Dewi. (2017). Pengaruh Model Pembelajaran Kooperatif Tipe Teams Games Tournament Terhadap Pemahaman Konsep Dan Kemampuan Komunikasi Matematis Siswa Kelas VIII SMPN DI Kecamatan Lubuk Begalung Padang. Jurnal Pendidikan dan Teknologi Informasi, 4 (1). 191-195.

Gazali, Rahmita Yuliana. (2016). Pembelajaran Matematika yang Bermakna. Math Didactic: Jurnal Pendidikan Matematika, 2(3). 181-190. 
Heruman. (2010). Model Pembelajaran Matematika di Sekolah Dasar. Bandung: PT Remaja Rosdakarya.

Hosnan. (2016). Psikologi Perkembangan Peserta Didik. Bogor: Ghalia Indonesia.

Isrok'atun dan Amelia Rosmala. (2018). Model-model Pembelajaran Matematika. Jakarta: PT Bumi Aksara.

Rahmat, Fitriyane Laila Apriliani, Suwatno, Rasto. 2018. Meningkatkan Pemahaman Konsep Siswa Melalui Teams Games Tournament, Sosio DIDAKTIKA:Social Science Education Journal, 5(1). 15-23.

Rusman. (2014). Model-model Pembelajaran: Mengembangkan Profesionalisme Guru Edisi Kedua. Jakarta: PT RajaGrafindo Persada.

Pangestuti, Ardian Anjar, Duran Corebima Aloysius, Siti Zubaedah. (2015). Using Reading Concept Map Teams Games Tournament (Remap-TGT) to Improve Reading Intetest of Tenth Grade Student of Laboratory Senior High School State University of Malang. American Journal of Educational Research, 3 (2). 250-254.

Salam, Abdus, Anwar Hossain, Shahidur Rahman. (2015). Effects of Using Teams Games Tournaments (TGT) Cooperative Technique for Learning Mathematics in Secondary Schools of Bangladesh. Malaysian Online Journal of Educational Technology,. 3 (3). 1-10.

Slavin, Robert E. (2005). Cooperative Learning. Bandung: Nusa Media.

Susanto, Ahmad. (2013). Teori Belajar Pembelajaran di Sekolah Dasar. Jakarta: Prenadamedia Group.

Syaifyrahman dan Tri Ujiati. (2013). Manajemen Dalam Pembelajaran. Jakarta: Indeks.

Uno, Hamzah B \& Satria Koni. (2013). Assesment Pembelajaran, Edisi I.Jakarta: Bumi Aksara. 